Materiales de Construcción

Vol. 70, Issue 340, October-December 2020, e231

ISSN-L: $0465-2746$

https://doi.org/10.3989/mc.2020.15719

\title{
Effect of different high surface area silicas on the rheology of cement paste
}

\author{
J. I. Tobón ${ }^{\mathrm{a}} \bowtie$, O. Mendoza ${ }^{\mathrm{b}}$, O.J. Restrepo ${ }^{\mathrm{a}}$, M.V. Borrachero ${ }^{\mathrm{c}}, \mathrm{J}$ Payá $^{\mathrm{c}}$
}

a. Grupo del Cemento y Materiales de Construcción CEMATCO, Universidad Nacional de Colombia, (Medellín, Colombia) b. Programa de Engenharia Civil/COPPE, Universidade Federal do Rio de Janeiro, (Río de janeiro, Brasil) c. Instituto de Ciencia y Tecnología del Hormigón ICITECH, Universitat Politècnica de València, (Valencia, Spain) $\triangle$ jitobon@unal.edu.co

Received 19 November 2019

Accepted 21 April 2020

Available on line 25 September 2020

\begin{abstract}
This work studies the effect of nanosilica (NS) on the rheology of cement paste by comparing it with two high specific surface area silicas: silica fume (SF) and pyrogenic silica (PS). Portland cement pastes were produced with different water-to-cementing material ratios and different solid substitutions of cement by silica. Water demand, setting time, and rheology tests were performed. Results showed that NS and SF decreased plastic viscosity, while PS increased it. Only PS was found to have an effect on yield stress. NS showed the most decreasing effect on viscosity, regardless of its higher water demand. It was concluded that the behavior of pastes containing NS and SF is governed by the "ball-bearing" effect from silica particles, by their agglomeration degree, and their impact on the solid volume fraction. The behavior of pastes containing PS is governed by its ability to absorb a portion of the mixing water.
\end{abstract}

KEYWORDS: Rheology; Workability; Superficial area; Pozzolan; Cement paste.

Citation/Citar como: Tobón, J.I.; Mendoza, O.; Restrepo, O.J.; Borrachero, M.V.; Payá, J. (2020) Effect of different high surface area silicas on the rheology of cement paste. Mater. Construcc. 70 [340], e231 https://doi.org/10.3989/ mc.2020.15719

RESUMEN: Efecto de diferentes sílices de alta área superficial sobre la reología de pastas de cemento. Este trabajo estudia el efecto de la nanosílice (NS) sobre la reología de pastas de cemento por comparación con sílices de alta área superficial: humo de sílice (SF) y pirosílice (PS). Las pastas fueron fabricadas con diferentes relaciones agua-material cementante y sustituciones sólidas de sílice. Fueron ejecutados ensayos de demanda de agua, tiempo de fraguado y reología. Se encontró que la NS y SF disminuyen la viscosidad plástica, mientras que la PS la aumenta. Solo la PS tuvo efecto sobre el límite elástico. La NS presentó mayor disminución de la viscosidad, independientemente de su alta demanda de agua. Se concluyó que el comportamiento de las pastas con NS y SF es gobernado por el efecto de "rodamiento" de la sílice, por su grado de aglomeración y por su impacto en la fracción de sólidos. El comportamiento de las pastas con PS es gobernado por su capacidad de absorber agua.

PALABRAS CLAVE: Reología; Trabajabilidad; Área superficial; Puzolana, Pasta de cemento.

ORCID ID: J. I. Tobón (https://orcid.org/0000-0002-1451-1309); O. Mendoza (https://orcid.org/0000-0002-42411321); O.J. Restrepo (https://orcid.org/0000-0003-3944-9369); M.V. Borrachero (https://orcid.org/0000-0002-78730658); J. Payá (https://orcid.org/0000-0001-7425-5311)

Copyright: (C) 2020 CSIC. This is an open-access article distributed under the terms of the Creative Commons Attribution 4.0 International (CC BY 4.0) License. 


\section{INTRODUCTION}

Amorphous silicas of high specific surface area (SSA), such as nanosilica (NS), silica fume (SF) and pyrogenic silica (PS), are a very reactive pozzolans that can be produced at industrial scale or obtained as by-products from several industrial processes (1). NS particles are spherical nanoparticles produced by different methods such as solgel or precipitation (2). SF particles, which are also spherical, exist from the nanometric to the micrometric scale usually as agglomerates. They are a condensate byproduct of high temperature processes such as the production of metallic silicon or iron-silicon alloys (3). PS particles are micrometric aggregates of individual nanometric silica particles, i.e. they have internal porosity, and are obtained though flame synthesis (4).

Blending the aforementioned pozzolans in Portland cement pastes, mortars, and concretes has been linked to positive effects such as acceleration on hydration rate, refinement of pore structure, enhancement of compressive strength, and increasing the durability $(5,6)$. On the other hand, it is known that high specific surface area materials in the granular mix increases the amount of water necessary to maintain the workability of the matrix, since more water is necessary to wet all the solid surfaces (7), introducing a rheological challenge.

Besides high SSA, morphology of the silica particles plays an important role in determining some fresh state properties of the matrix such as water and superplasticizer demands, setting time and hydration kinetics (8). While the porous structure of PS particles is capable of absorbing a portion of the mixing water, worsening workability, the spherical nature of SF creates a "ball-bearing" effect that decreases the friction between particles moving past each other more easily (9-11). The "ball-bearing" effect is not exclusive of silica particles, other spherical components, such as entrapped air bubbles $(12,13)$, are capable of inducing it.

It has been reported that NS increases the water demand of cement paste, worsening its workability in some addition ranges (14). It also has also been reported that NS is capable of inducing a "ball-bearing" effect, improving workability of concretes (15). This raises the question of which characteristic of NS is more dominant over the rheological behavior of cement-based matrices, its elevated water demand or its spherical particle spherical morphology. Thus, this work aims to understand the effect of NS on the rheology of Portland cement paste by comparing it with two other high SSA silicas of different size/morphology: SF and PS.

\section{EXPERIMENTAL PROCEDURES}

\subsection{Materials}

The materials used in this study were: Portland cement type III produced by Argos Colombia; an aqueous dispersion of nanosilica particles produced by BASF Chemicals (NS); powdered pyrogenic silica produced by Glassven (PS); and powdered silica fume produced by BASF Chemicals (SF).

\subsection{Materials characterization}

Physical and chemical characterizations of the raw materials were performed to obtain their chemical composition, particle size distribution, particle morphology and specific surface area. Chemical composition was obtained by X-Ray fluorescence using an ARL 8680s Total Cement Analyzer equipment, following the ASTM C114-03 standard in $\mathrm{B}_{4} \mathrm{Li}_{2} \mathrm{O}_{7}$ pills. Specific surface area (SSA) was obtained in a Micrometrics Gemini V 2380 surface area analyzer, using $\mathrm{N}_{2}$ adsorption and the BET method. Particle size of SF and PS was measured by dynamic light scattering (DLS), using a Mastersizer equipment from Malvern. Particle size of NS was measured by laser diffraction using a Zetasizer equipment from Malvern.

Morphology of the particles was characterized using Transmission Electron Microscopy (TEM) images acquired in a TECNAI 20 Twin microscope from FEI, using an acceleration of $200 \mathrm{kV}$. Each sample was dispersed in ethanol $\left(\mathrm{C}_{2} \mathrm{H}_{5} \mathrm{OH}\right)$ and sonicated for $30 \mathrm{~min}$ in an ultrasonic bath prior to imaging. After sonication, an aliquot of the sample was dropped in a Fomvar 300 cupper mesh and coated with carbon. Electrophoretic mobility values were determined using $\zeta$-potential measurements in a Zetasizer nanoZS equipment from Malvern. The $\mathrm{pH}$ of the dispersions was varied from neutral to basic using ammonium hydroxide $\left(\mathrm{NH}_{4} \mathrm{OH}\right)$ in deionized water. Each sample was placed in a disposable capillary cell stabilized at $25^{\circ} \mathrm{C}$, $\zeta$-potential was determined 3 times for each $\mathrm{pH}$ value.

\subsection{Tests on cement paste}

Cement pastes were produced using $0 \%, 5 \%$ and $10 \%$ mass substitutions of cement by silica. Setting time and normal consistency were performed for each paste following ASTM C191 and ASTM C187 standards respectively. Pastes for rheology were mixed manually using water-to-cementing material $(\mathrm{w} / \mathrm{cm})$ ratios of $0.45,0.50,0.55$ and 0.60 . Nomenclature and detailed composition of the studied samples are presented in Table 1. Flow curves were obtained 5 minutes after the first contact between cement and water using a Bohlin 
TABLE 1. Nomenclature and composition by mass of the studied pastes.

\begin{tabular}{lccc}
\hline Paste & w/cm & \% Cement & \% Silica \\
\hline REF & & 100 & 0 \\
$5 \% \mathrm{NS}$ & & 95 & 5 \\
$10 \% \mathrm{NS}$ & & 90 & 10 \\
$5 \% \mathrm{SF}$ & $0.45,0.50,0.55$ & 95 & 5 \\
$10 \% \mathrm{SF}$ & and 0.60 & 90 & 10 \\
$5 \% \mathrm{PS}$ & & 95 & 5 \\
$10 \%$ PS & & 90 & 10 \\
\hline
\end{tabular}

Instruments C-VOR 200 rheometer. A vane-in-cup geometry with a $25 \mathrm{~mm}$ diameter vane tool in a smooth cylindrical cup with a $1 \mathrm{~mm}$ gap was used. Each paste was pre-sheared at a shear rate $(\dot{\gamma})$ of $10 \mathrm{~s}^{-1}$ for 60 seconds, subsequently, shear rate was increased to $250 \mathrm{~s}^{-1}$ at a $20 \mathrm{~s}^{-1} / \mathrm{min}$ rate, maintained for 3 minutes at this value, and decreased to $0 \mathrm{~s}^{-1}$ also at a $20 \mathrm{~s}^{-1} / \mathrm{min}$ rate. Both during the shear rate increase and decrease 50 evenly distributed shear stress $(\tau)$ points were acquired. The test had a duration of $28 \mathrm{~min}$, which added to the initial 5 minutes of sample preparation, gives a total duration of 33 min after the first contact of cement with water.

\section{RESULTS AND DISCUSSION}

\subsection{Materials characterization}

Physical, chemical and mineralogical characterization results obtained for the three studied silica are presented in Table 2 and Figure 1. It was confirmed that NS, SF and PS are mainly composed of amorphous silica, finding only minor crystalline minerals in SF probably from its production process. Regarding their surface area and average particle size, high SSA values were found for all silica samples, while NS presented a $d_{50}$ in the scale on nanometers and SF and PS presented $\mathrm{a} \mathrm{d}_{50}$ in the scale of micrometers. It should be noticed that the obtained SSA values for SF and PS are not compatible with the particle sizes found, especially for PS. Density $(\rho)$ of the cement used was $3.17 \mathrm{~g} / \mathrm{cm}^{3}$. Density of the silicas are presented in Table 2. Average particle size from BET result was computed as $\mathrm{d}_{\mathrm{BET}}=6000 /(\mathrm{SSA} \cdot \rho)$. The agglomeration factor $\left(\mathrm{F}_{\mathrm{AG}}\right)$ of the silicas was defined as $\mathrm{F}_{\mathrm{AG}}=\mathrm{d}_{50} / \mathrm{d}_{\mathrm{BET}}(16)$.

TEM images were used to understand the incompatibility between average particle size and surface specific area of SF and PS. One typical image of each silica studied is presented in Figure 2. NS was found to be composed of spheres with individual particle sizes compatible with the $d_{50}$ value measured by laser diffraction. SF and PS were found to be composed of agglomerated particles with
TABLE 2. Physical and chemical characteristics of NS, SF and PS.

\begin{tabular}{lrrr}
\hline Parameter & \multicolumn{1}{c}{ NS } & \multicolumn{1}{c}{ SF } & \multicolumn{1}{c}{ PS } \\
\hline $\mathrm{SiO}_{2}(\%)$ & 93.56 & 92.84 & 87.21 \\
$\mathrm{Al}_{2} \mathrm{O}_{3}(\%)$ & 0.00 & 0.22 & 0.00 \\
$\mathrm{Fe}_{2} \mathrm{O}_{3}(\%)$ & 0.39 & 1.00 & 0.13 \\
$\mathrm{CaO}(\%)$ & 0.22 & 0.46 & 0.13 \\
$\mathrm{MgO}(\%)$ & 0.13 & 0.75 & 0.13 \\
$\mathrm{Na}_{2} \mathrm{O}(\%)$ & 0.62 & 0.26 & 1.00 \\
$\mathrm{~K}_{2} \mathrm{O}(\%)$ & 0.02 & 0.44 & 0.01 \\
$\mathrm{SO}_{3}(\%)$ & 0.30 & 0.31 & 0.86 \\
$\mathrm{Cr}_{2} \mathrm{O}_{5}(\%)$ & 0.04 & 0.00 & 0.00 \\
$\mathrm{MnO}(\%)$ & 0.01 & 0.03 & 0.01 \\
$\mathrm{P}_{2} \mathrm{O}_{5}(\%)$ & 0.13 & 0.16 & 0.12 \\
$\mathrm{TiO}_{2}(\%)$ & 0.02 & 0.01 & 0.04 \\
Loss on ignition $(\%)$ & 4.46 & 3.01 & 10.01 \\
\hline Average size - $\mathrm{d}_{50}(\mu \mathrm{m})$ & 0.098 & 83.7 & 23.6 \\
$\mathrm{Specific} \mathrm{surface}$ area $-\mathrm{SSA}\left(\mathrm{m}^{2} / \mathrm{g}\right)$ & 51.4 & 28.0 & 147.9 \\
Density - $\rho\left(\mathrm{g} / \mathrm{cm}^{3}\right)$ & 1.12 & 2.06 & 1.98 \\
$\mathrm{~d}_{\mathrm{BET}}(\mu \mathrm{m})$ & 0.104 & 0.021 & 0.104 \\
Agglomeration factor $-\mathrm{F}_{\text {AG }}$ & 0.94 & 1151.84 & 804.64 \\
\hline
\end{tabular}

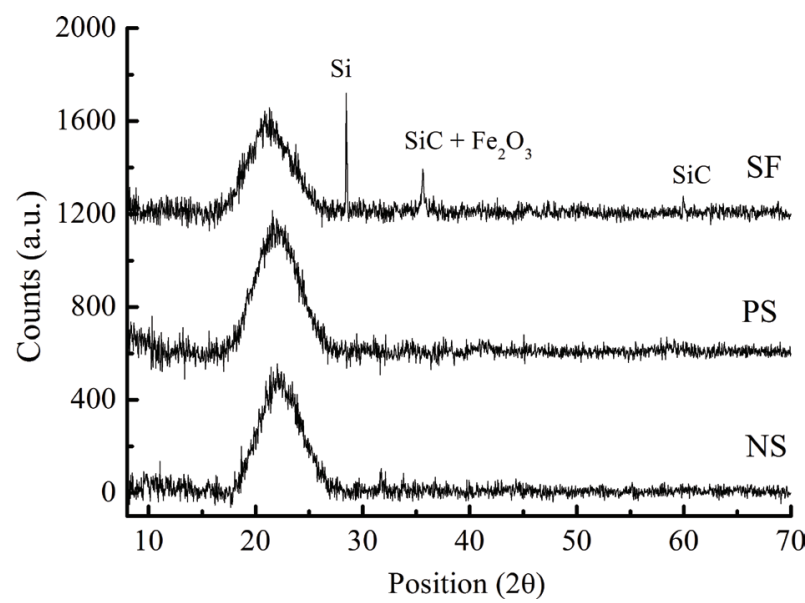

FIGURE 1. X-Ray diffraction patterns obtained for NS, SF and PS (a.u.: arbitrary units).

individual sizes much smaller than the $\mathrm{d}_{50}$ measured by dynamic light scattering. This indicates that particle size experiments were able to capture the average size of the agglomerates, while SSA experiments were able to capture the surface area of the individual components. The $\mathrm{F}_{\mathrm{AG}}$ results confirmed that while NS particles and be considered completely dispersed, the SF and PS particles can be considered highly agglomerated (17).

A morphological difference was also identified among NS, SF and PS. While NS and SF were found to be made of spherical particles, PS was found to 
be made of connected chain-like elements, which correspond to silica droplets of pyrogenic origin (4).

The tendency to agglomerate of the three silicas at different $\mathrm{pH}$ values was studied through $\zeta$-potential measurements. The obtained results are presented in Figure 3. Elevated $\mathrm{pH}$ values were used to emulate the typical alkaline environment generated by cement hydration, which depending on the hydration degree, alkalis, calcium silicates and $\mathrm{CaO}$ concentrations, can reach values around 12.5 in the pore solution (18). The $\zeta$-potential results are separated in two areas, one under $-25 \mathrm{mV}$, where the colloidal suspension of silica particles in water can be considered stable, and above $-25 \mathrm{mV}$ where it can be considered unstable (19). These areas are separated by a horizontal solid line in Figure 3.

NS, SF and PS present a clear tendency to decrease (absolute value) their $\zeta$-potential with the increase of $\mathrm{pH}$ but without reaching the isoelectric point. NS had the lowest $\zeta$-potential, always in the stable zone for the entire $\mathrm{pH}$ range studied. On the other hand, $\zeta$-potential values for PS and SF approached or surpassed $-25 \mathrm{mV}$ at $\mathrm{pH}$ values of 12 or higher. This indicates that in the typical environment generated by cement hydration, PS and SF can be considered metastable or unstable with a tendency to agglomerate. SF was found to be prone to agglomeration at a $\mathrm{pH}$ of 7 , this helps to explain why particle size microscopy images showed particle agglomerates rather than individual ones, since both these tests were carried out in deionized water, which has a typical $\mathrm{pH}$ of approximately 7 .

\subsection{Water demand and setting time}

Water demand and setting time of Portland cement pastes were considered two important properties that can be modified by NS, SF and PS additions and might lead to misinterpretations of the rheology results if not taken into account. Water demand was studied through normal consistency tests, while setting time was studied using Vicat's needle. Results are presented in Table 3. It was found that water demand increased proportionally to the amount of silica blended in the paste, being PS the silica that demanded more water for both percentages studied, followed by NS and SF. It should be noticed that the increase in water demand appears to be also proportional to the SSA of each silica, as previously demonstrated by the authors (8). The porous nature of PS should also be taken into account, since it is capable of absorbing water, further increasing the water demand of the pastes blended with it.

Regarding setting time, for all silica studied, the initial and final setting times increased when compared to the reference paste, this as a direct consequence of the increase of $\mathrm{w} / \mathrm{cm}$ (being $\mathrm{cm}$ the cementing material, in this study the sum of cement and silica), necessary to attain normal consistency. Additionally, when comparing the $5 \%$ and $10 \%$ solid substitutions of NS and SF, it can be seen that higher amounts of silica led to a decrease in setting time: this is associated with nucleation effects activity (6). For PS this was not the case, indicating that any nucleation effects from PS could not overcome the delaying effect of the additional water in the mix. Overall, initial setting times for all pastes are much higher than the total testing time of each rheological experiment (33 minutes).

\subsection{Rheological measurements}

Rheological experiments were carried out in cement pastes following the proportions presented in Table 1. A Bingham model $\tau=\tau_{0}+\mu_{0}$, where $\tau_{0}$ is

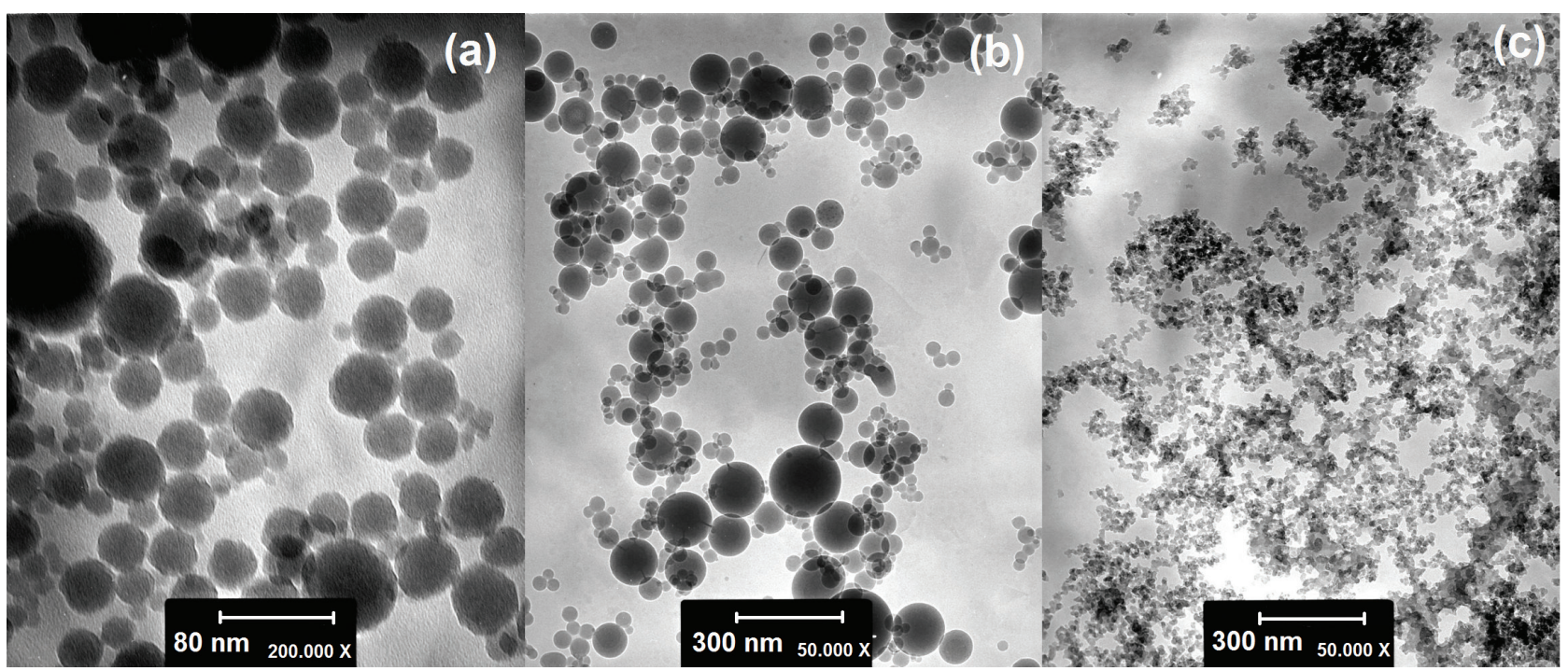

Figure 2. TEM images of (a) NS, (b) SF and (c) PS. 
yield stress and $\mu_{0}$ is plastic viscosity, was fitted to the linear descending portion of each flow curve. Fitting was carried out only in the linear part of the descending portion, in this case between 100 and

TABLE 3. Water demand and setting time of Portland cement pastes blended with NS, SF and PS (5 and $10 \%$ solid substitutions).

\begin{tabular}{lcccc}
\hline & $\begin{array}{c}\text { w/cm for } \\
\text { normal } \\
\text { consistency }\end{array}$ & $\begin{array}{c}\text { Initial } \\
\text { setting } \\
\text { time (min) }\end{array}$ & $\begin{array}{c}\text { Final } \\
\text { Setting } \\
\text { time (min) }\end{array}$ & $\begin{array}{c}\text { Setting } \\
\text { time (min) }\end{array}$ \\
\hline REF & 0.28 & 112 & 143 & 31 \\
$5 \% \mathrm{NS}$ & 0.37 & 131 & 160 & 29 \\
$10 \% \mathrm{NS}$ & 0.42 & 133 & 160 & 27 \\
$5 \% \mathrm{SF}$ & 0.30 & 149 & 207 & 58 \\
$10 \% \mathrm{SF}$ & 0.32 & 154 & 204 & 50 \\
$5 \% \mathrm{PS}$ & 0.44 & 142 & 233 & 91 \\
$10 \% \mathrm{PS}$ & 0.56 & 125 & 241 & 116 \\
\hline
\end{tabular}

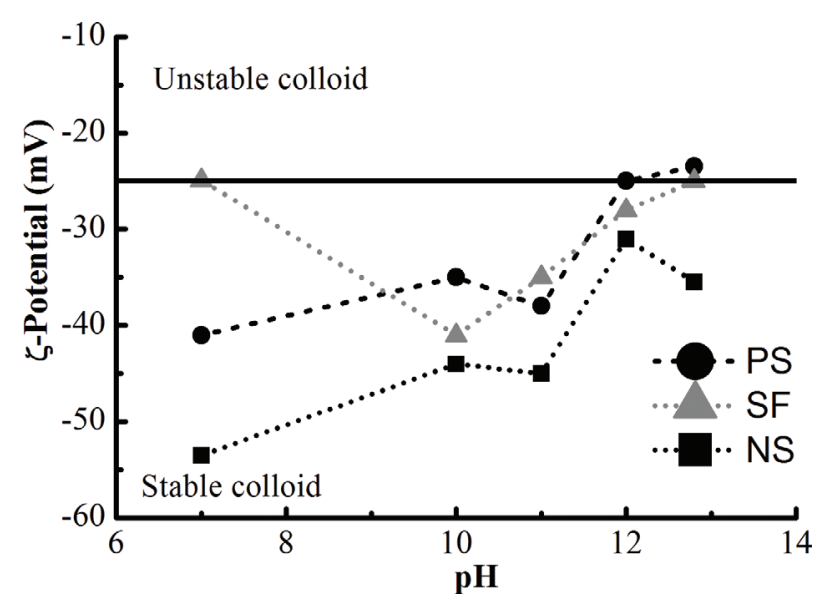

FIGURE 3. $\zeta$-potential values for NS, SF and PS at different $\mathrm{pH}$ values.

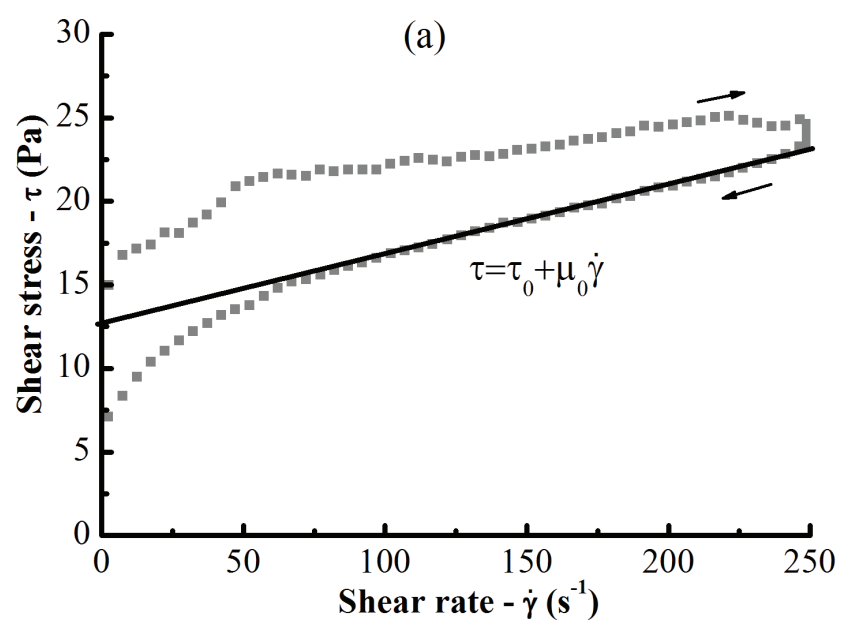

$250 \mathrm{~s}^{-1}$ for all samples. A typical flow curve with its corresponding fitted Bingham model, and a typical instantaneous viscosity versus shear rate curve, are presented in Figure 4. Pastes containing 5\%PS at $\mathrm{w} / \mathrm{cm} 0.45$, and $10 \% \mathrm{PS}$ at $\mathrm{w} / \mathrm{cm} 0.45,0.50$ and 0.55 , could not be placed in the vane-in-cup geometry due to their low workability. All testes pastes presented a viscoelastic shear-thinning behavior, as expected.

All the plastic viscosity $\left(\mu_{0}\right)$ and yield stress $\left(\tau_{0}\right)$ values obtained are presented in Figures 5 and 6 respectively. For the reference paste, i.e. without any silica blend, it was found that $\mu_{0}$ and $\tau_{0}$ decreased with the increase of water in the mixture, as expected. More water in an unit volume of paste increases the mean distance between particles, decreasing their number of contact points and attractive forces (decreasing $\tau_{0}$ ), facilitating sliding motions between them (decreasing $\mu_{0}$ ) (20). This result was used as reference to understand the effects of NS, SF and PS.

NS and SF were found to decrease $\mu_{0}$ with respect to the reference paste in the entire $w / \mathrm{cm}$ range studied, being NS always more effective in terms of reducing plastic viscosity. This was found to be true for both $5 \%$ and $10 \%$ substitutions. This behavior, known as "ball-bearing" effect, is typical of spherical air bubbles and spherical mineral additions, which allow particles to move past each other more easily (21). The increase in packing density, expected to be induced by the solid substitutions of cement by NS and SF, also plays an important role on the decreasing in $\mu_{0}$ (20). On the other hand, PS was found to increase $\mu_{0}$ due to its open porous structure, which potentially absorbs a portion of the mixing water (22) and decreases the effective amount of water in the liquid medium. Only the $5 \% \mathrm{PS}$ paste at w/cm of 0.60 presented a $\mu_{0}$ value similar to that of the reference sample with $\mathrm{w} / \mathrm{cm}=0.60$, indicating

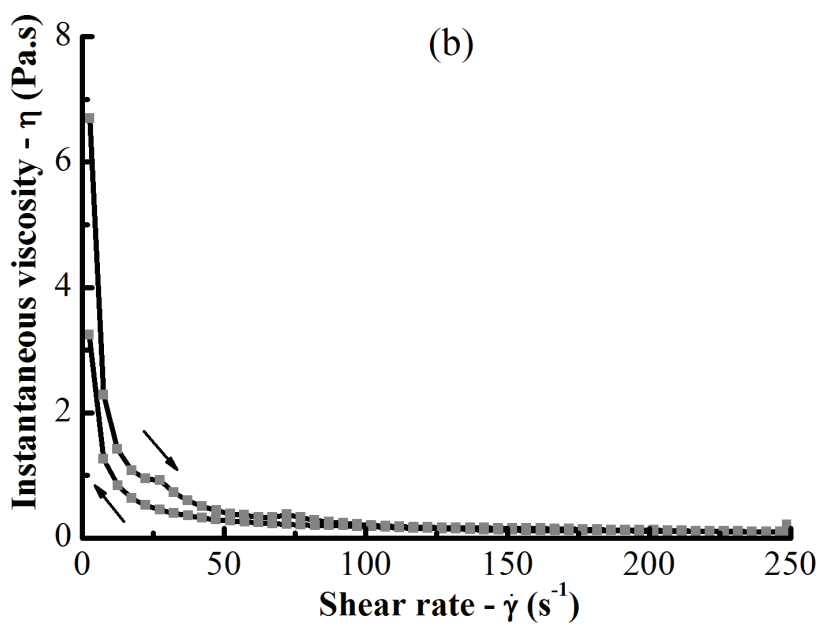

FIgURE 4. (a) Typical flow curve obtained for the studied pasted showing a Bingham model fitted to the linear descending portion of the curve, (b) typical instantaneous viscosity curve obtained for the studied pastes. 

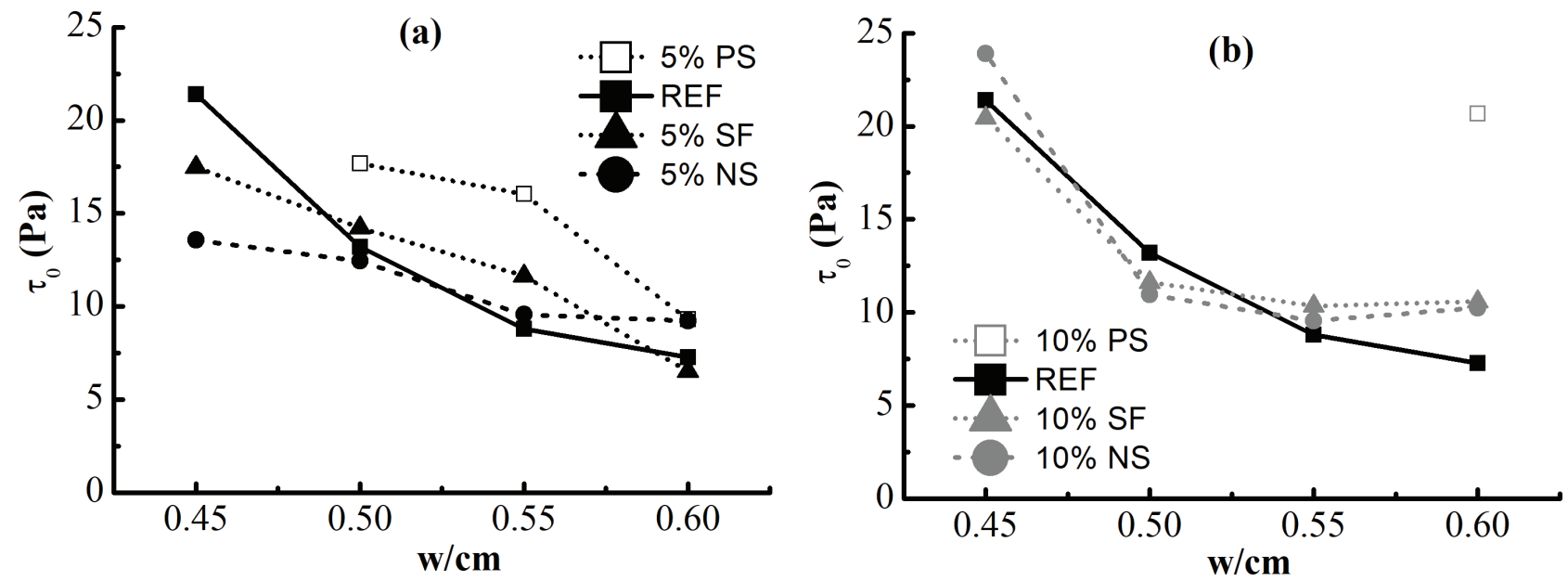

Figure 5. Plastic viscosity $\left(\mu_{0}\right)$ results obtained for pastes blended with (a) $5 \%$ and (b) $10 \%$ of NS, SF and PS.
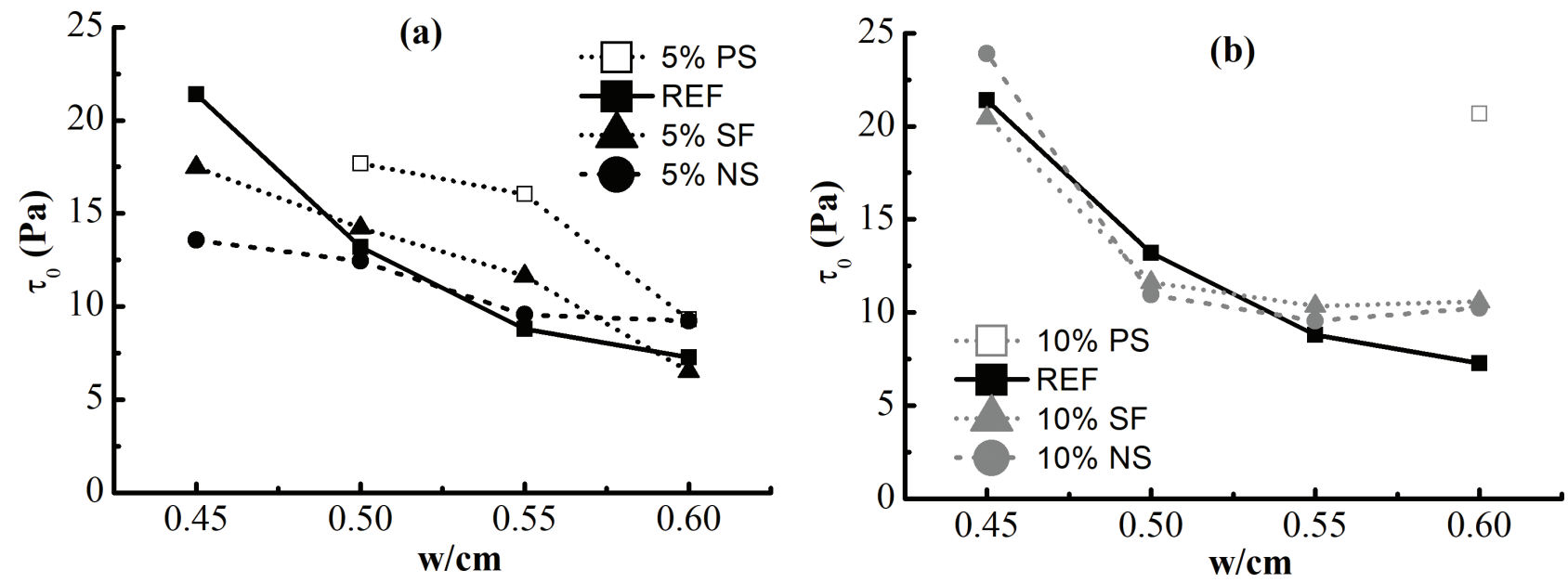

FIGURE 6. Yield stress from the Bingham model $\left(\tau_{0}\right)$ results obtained for pastes blended with (a) $5 \%$ and (b) $10 \%$ of NS, SF and PS.

that for this water content the pores in PS might have saturated and more water was available in the matrix. On the other hand, $10 \%$ PS mix only was rheologically measured for $\mathrm{w} / \mathrm{cm}=0.6$ and the corresponding plastic viscosity was much higher than reference: $0.11 \mathrm{~Pa}$.s versus $0.03 \mathrm{~Pa}$.s. In this case, the effective water was very low and the plastic viscosity was indeed much higher than that obtained for the reference mix with w/cm $=0.45$.

Regarding yield stress, NS and SF were found to have from little to no impact over $\tau_{0}$, following the overall trend imposed by the variation of $w / \mathrm{cm}$ ratio. PS was found to increase slightly $\tau_{0}$ probably due to the amount of water potentially absorbed by it, which increases the contact points between particles, this leads to a less pronounced effect than the one over $\mu_{0}$, which is more dependent on the amount of water in the media (20).

\section{FINAL DISCUSSION}

To obtain a general visualization of the effect of the studied silicas over the rheological behavior of cement paste, $\mu_{0}$ versus $\tau_{0}$ plot for all pastes studied, separated by silica type, are presented in Figure 7. The effect of water content on the properties of the reference paste was taken as baseline for interpretation and is presented as a solid line. It is clear that PS followed trend opposite to that followed by NS and SF. While PS induced a displacement to the right of the reference mix, NS and SF induced a displacement to the left. The only paste containing PS located to the left of the reference paste line was the one with $5 \% \mathrm{PS}$ at w/cm 0.60 .

The solid fraction of each paste studied was computed by dividing the volume of solids (cement + silica) by the total volume of paste. The obtained 


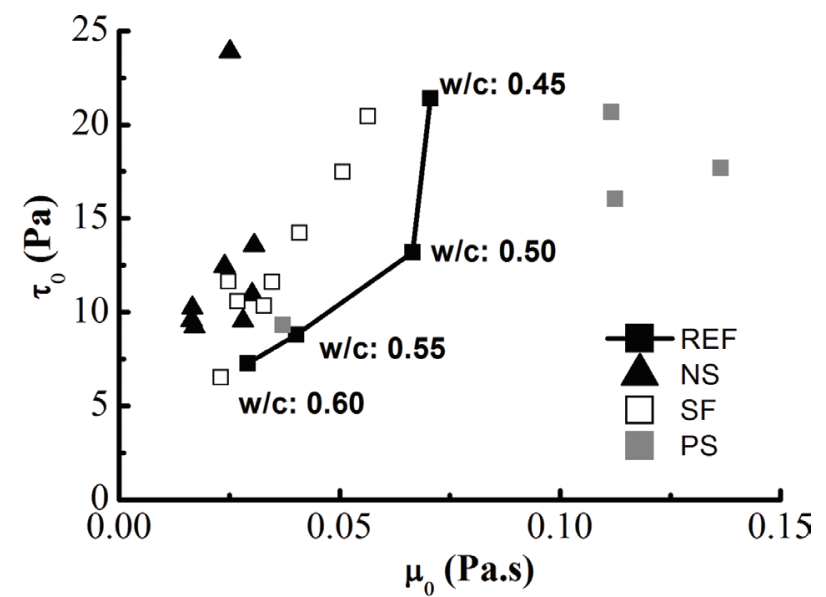

FIGURE 7. $\mu_{0}$ versus $\tau_{0}$ plot for all pastes studied in this work. (Solid line: effect of water content).

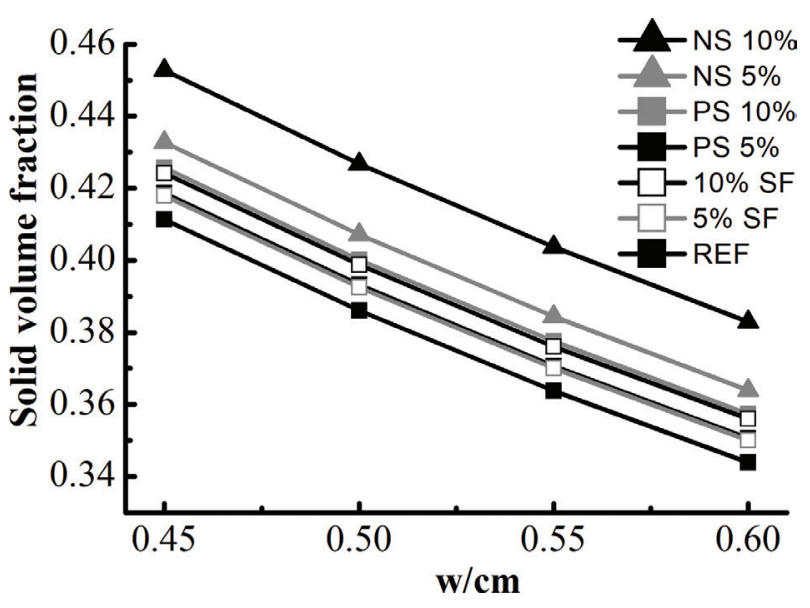

FIGURE 8. Solid volume fraction results of Portland cement pastes blended with NS, SF and PS. results are presented in Figure 8. A higher value for solid volume fraction indicates a decrease in empty space that would be occupied by water; thus, decreasing the viscosity of the paste. It was found that all pastes presented an increasing solid volume fraction since cement was substituted by less dense materials. This higher volume fraction was translated into lower $\mu_{0}$ results for NS and SF, indicating that the "ball-bearing" effect is not the only factor contributing to the decrease in viscosity of the paste. PS did not follow this trend due to its water absorption capacity.

To better visualize the effect of the solid fraction modifications on the rheological behavior of the studied pastes, $\mu_{0}$ and $\tau_{0}$ were plotted versus their corresponding volumetric solid fraction are presented in Figure 9 and Figure 10 respectively.

Three main factors were identified as relevant to understand the behaviors shown in Figure 8: (i) "ball-bearing" effect, (ii) water demand and (iii) $\xi$-potential. The role of each one of these factors is discussed as follows:

(i) Water demand: while water demand results were found to be proportional to the SSA and amount of silica blended in each paste, as expected (8), $\mu_{0}$ results did not follow the same trend. It should be taken into account that is due to its porous structure: PS is capable of absorbing water (22), decreasing the amount of water available in the medium and further increasing $\mu_{0}$. Additionally, NS presented higher water demand than SF, but generated pastes with lower $\mu_{0}$, indicating that other factors seem to have a higher influence on viscosity.

(ii) "Ball-bearing" effect and solid fraction: NS and $\mathrm{SF}$, which present similar trends towards lower $\mu_{0}$ values, have similar spherical morphologies
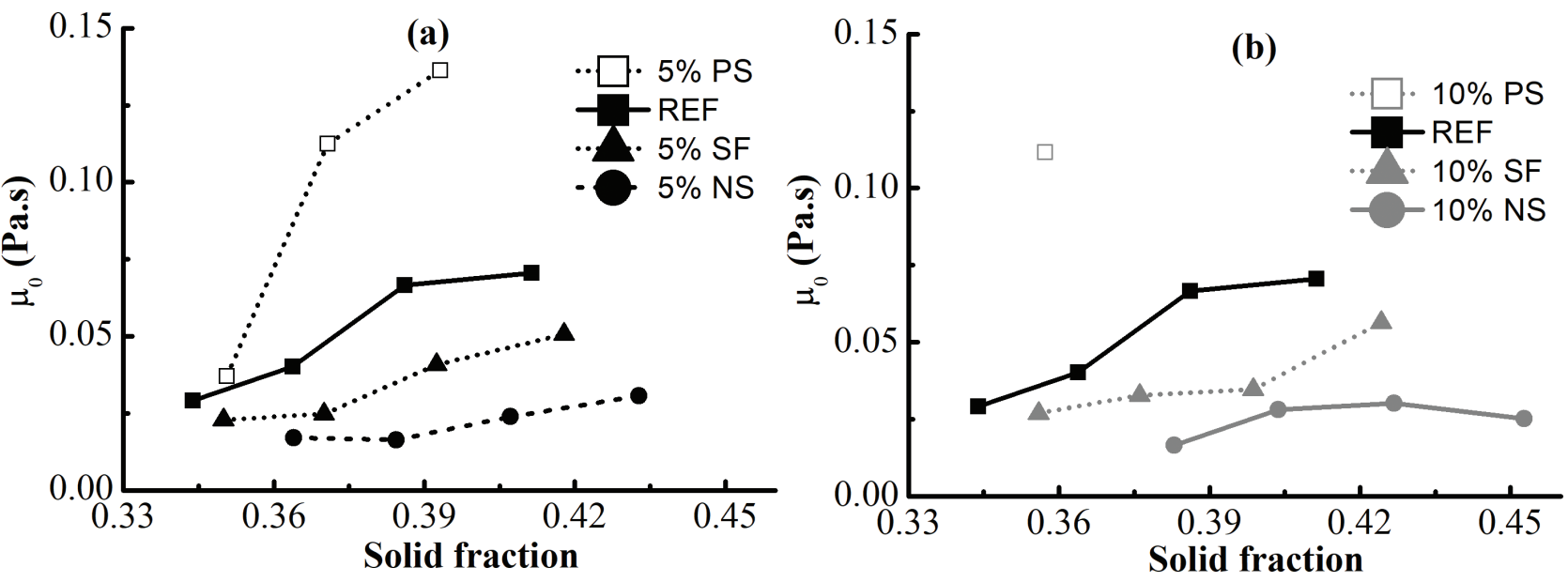

FIGURE 9. Plastic viscosity $\left(\mu_{0}\right)$ versus solid fraction for pastes blended with (a) $5 \%$ and (b) $10 \%$ of NS, SF and PS. 

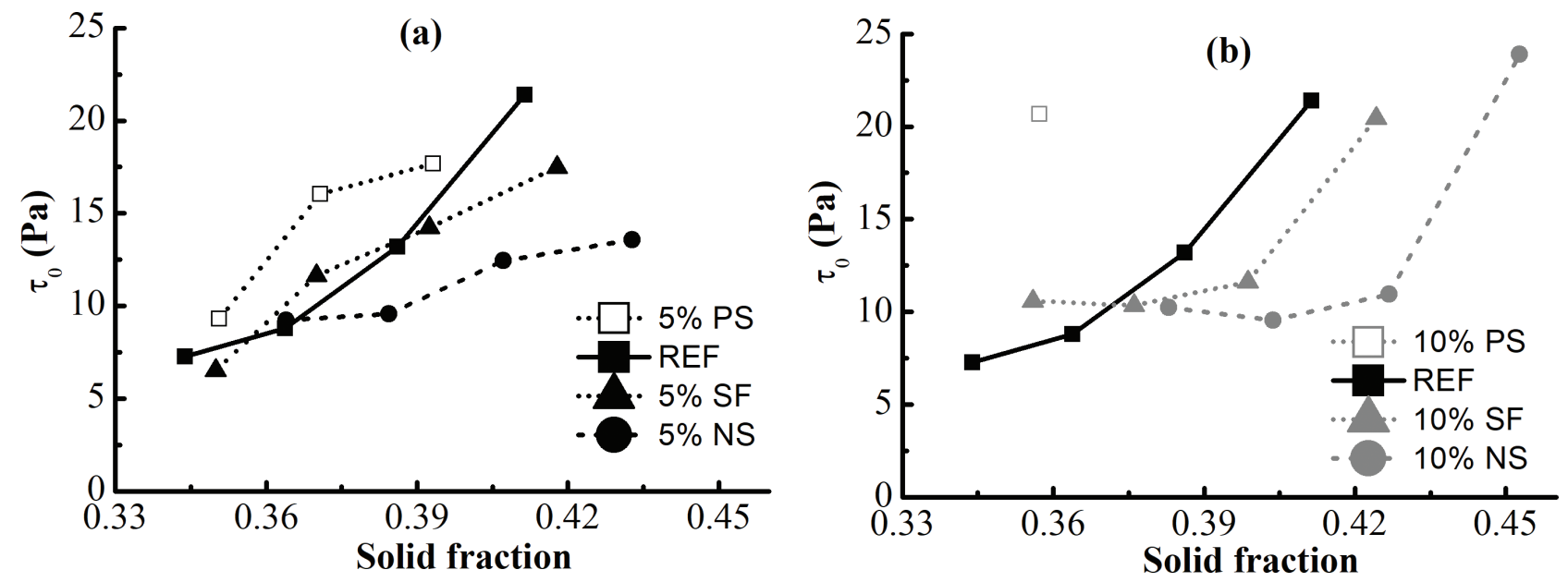

Figure 10. Yield stress from the Bingham model $\left(\tau_{0}\right)$ versus solid fraction for pastes blended with (a) $5 \%$ and (b) $10 \%$ of NS, SF and PS.

at different size scales. This, contrasted with the chain-like morphology of PS, supports the existence of "ball-bearing" effects at the nanometric scale. Experiments in other types of materials such as polymers have reported ballbearing effect caused by NS (23). Nevertheless, increases in solid fraction of the granular matrix due to the solid substitution of cement by less dense materials may affect the magnitude of the "ball-bearing" effect. Further experiments should be carried out to decouple these phenomena.

(iii) $\xi$-potential: it is known that during the first minutes of hydration, $\mathrm{pH}$ of the liquid phase elevates rapidly (24). At $\mathrm{pH}$ values of 12 or higher PS and SF approach the metastable or unstable dispersion zone, while NS remains in the stable zone. This might explain why NS is more effective in lowering $\mu_{0}$ than SF. The stability of the NS colloidal suspension can be consequence of the presence of a dispersing agent on their surface, or more likely, electrical charges from functionalization. This parameter was not disclosed by the manufacturer. Agglomerations or flocculates of SF are less efficient in inducing a "ball-bearing" effect than well dispersed NS particles.

\section{CONCLUSIONS}

Experimental results obtained in this work allow concluding that:

- NS and SF particles decrease the viscosity of the paste while having little to none effect on the yield stress. This can be related to the presence of a "ball-bearing" effect induced by the particles and to their lower density compared to cement, which increases the solid volume fraction of the granular matrix.

- PS particles increase both viscosity and yield stress of the paste due to their porous structure capable of absorbing an important portion of the mixing water.

- Regardless of the high water demand of the studied silicas, the rheological behavior of pastes containing NS and SF is mainly governed by the geometry and dispersion degree of the spherical silica particles in the matrix, while the behavior of pastes containing PS is governed by the ability of the silica to absorb a portion of the mixing water in its porous structure.

\section{REFERENCES}

1. Kwan, A.K.H.; Li, Y. (2013) Effects of fly ash microsphere on rheology, adhesiveness and strength of mortar. Constr. Build. Mater. 42, 137-145. https://doi.org/10.1016/j. conbuildmat.2013.01.015.

2. Jal, P.K.; Sudarshan, M.; Saha, A.; Patel, S.; Mishra, B.K. (2004) Synthesis and characterization of nanosilica prepared by precipitation method. Coll. Surf. A Physicochem. Eng. Asp. 240 [1-3], 173-178. https://doi.org/10.1016/j. colsurfa.2004.03.021.

3. El Sokkary, T. M.; Assal, H. H.; Kandeel, A. M. (2004) Effect of silica fume or granulated slag on sulphate attack of ordinary portland and alumina cement blend. Ceram. Int. 30 [2], 133-138. https://doi.org/10.1016/ S0272-8842(03)00025-7.

4. Gutsch, A.; Krämer, M.; Michael, G.; Mühlenweg, H.; Pridöhl, M.; Zimmermann, G. (2002) Gas-Phase production of nanoparticles. KONA Powder Part. J. 20, 24-37. https://doi.org/10.14356/kona.2002008.

5. Singh, L.P.; Karade, S.R.; Bhattacharyya, S.K.; Yousuf, M.M.; Ahalawat, S. (2013) Beneficial role of nanosilica in cement based materials - A review. Constr. Build. Mater. 47, 1069-1077. https://doi.org/10.1016/j. conbuildmat.2013.05.052

6. Björnström, J.; Martinelli, A.; Börjesson, L.; Panas, I.; (2004) Accelerating effects of colloidal nano-silica for beneficial calcium-silicate-hydrate formation in cement. Chem. 
Phys. Lett. 392 [1-3], 242-248. https://doi.org/10.1016/j. cplett.2004.05.071.

7. Mendoza Reales, O.A.; Silva, E.C.C.M.; Paiva, M.D.M.; M.; Duda, P.; Toledo Filho, R.D. (2017) The role of surface area and compacity of nanoparticles on the rheology of cement paste 25.3. ACI Symp. Pub. 320, 25.1-25.14. https:// www.concrete.org/publications/internationalconcreteabstr actsportal $/ \mathrm{m} /$ details/id $/ 51701063$.

8. Tobón, J. I.; Mendoza Reales, O; Retrepo, O.J; Borrachero, M.V. (2018) Effect of pyrogenic silica and nanosilica on Portland cement matrices. J. Mater. Civ. Eng. 30 [10], 1-10. https://doi.org/10.1061/(asce)mt.1943-5533.0002482.

9. Mehdipour, I.; Khayat, K.H. (2018) Understanding the role of particle packing characteristics in rheo-physical properties of cementitious suspensions: A literature review. Constr. Build. Mater. 161, 340-353. https://doi. org/10.1016/j.conbuildmat.2017.11.147.

10. Boukendakdji, O.; Kadri, E.H.; Kenai, S. (2012) Effects of granulated blast furnace slag and superplasticizer type on the fresh properties and compressive strength of selfcompacting concrete. Cem. Concr. Compos. 34 [4], 583-590. https://doi.org/10.1016/j.cemconcomp.2011.08.013

11. Park, C.K.; Noh, M.H.; Park, T.H. (2005) Rheological properties of cementitious materials containing mineral admixtures. Cem. Concr. Res. 35 [5], 842-849. https://doi. org/10.1016/j.cemconres.2004.11.002.

12. Deng, H.; Li, H. (2018) Assessment of self-sensing capability of carbon black engineered cementitious composites. Constr. Build. Mater. 173, 1-9. https://doi.org/10.1016/j. conbuildmat.2018.04.031.

13. Mendoza-Reales, O.A.; Arias Jaramillo, Y.P.; Ochoa Botero, J.C.; Delgado, C.A.; Quintero, J.H.; Toledo Filho, R.D. (2018) Influence of MWCNT/surfactant dispersions on the rheology of Portland cement pastes. Cem. Concr. Res. 107, 101-109. https://doi.org/10.1016/j.cemconres.2018.02.020.

14. Quercia, G.; Hüsken, G.; Brouwers, H.J.H. (2012) Water demand of amorphous nano silica and its impact on the workability of cement paste. Cem. Concr. Res. 42 [2], 344-357. https://doi.org/10.1016/j.cemconres.2011.10.008.

15. Norhasri, M.S.M. Hamidah, M.S.; Fadzil, A.M. (2017) Applications of using nano material in concrete: A review.
Constr. Build. Mater. 133, 91-97. https://doi.org/10.1016/j. conbuildmat.2016.12.005.

16. Bowen, P. (2002). Particle size distribution measurement from millimeters to nanometers and from rods to platelets. J. Dispers. Sci. Technol. 23 [5], 631-662. https://doi. org/10.1081/DIS-120015368.

17. Staiger, M.; Bowen, P.; Ketterer, J.; Bohonek, J. (2002) Particle size distribution measurement and assessment of agglomeration of commercial nanosized ceramic particles. J. Dispers. Sci. Technol. 23 [5], 619-630. https://doi. org/10.1081/DIS-120015367.

18. Hidalgo, A.; Petit, S.; Domingo, C.; Alonso, C.; Andrade, C. (2007) Microstructural characterization of leaching effects in cement pastes due to neutralisation of their alkaline nature. Part I: Portland cement pastes. Cem. Concr. Res. 37 [1], 63-70. https://doi.org/10.1016/j.cemconres. 2006.10.002

19. Srinivasan, S.; Barbhuiya, S.A.; Charan, D.; Pandey, S.P. (2010) Characterising cement-superplasticiser interaction using zeta potential measurements. Constr. Build. Mater. 24 [12], 2517-2521. https://doi.org/10.1016/j. conbuildmat.2010.06.005.

20. de Larrard, F. (1999) Concrete mixture proportioning a scientific approach, E. \& F.N. Spon, London.

21. Banfill, P.F.G. (2006) Rheology of fresh cement and concrete. Rheol. Reviews 2006. 61-130. https://doi.org/ 10.4324/9780203473290.

22. Burneau, A.; Barres, O.; Gallas, J.P.; Lavalley, J.C. (1990) Comparative Study of the Surface Hydroxyl Groups of Fumed and Precipitated Silicas. 2. Chatracterization by infrared spectroscopy of the interacctions with water. Langmuir. 6 [8], 1364-1372. https://doi.org/10.1021/la00098a008.

23. Xie, X-L.; Liu, Q-X.; Li, R.K-Y.; Zhou, X-P.; Zhang, Q-X.; Yu, Z-Z.; Mai, Y-W. (2004) Rheological and mechanical properties of $\mathrm{PVC} / \mathrm{CaCO}_{3}$ nanocomposites prepared by in situ polymerization. Polymer. 45 [19], 6665-6673. https:// doi.org/10.1016/j.polymer.2004.07.045.

24. Asavapisit, S.; Fowler, G.; Cheeseman, C.R. (1997) Solution chemistry during cement hydration in the presence of metal hydroxide wastes. Cem. Concr. Res. 27 [8], 1249-1260. https://doi.org/10.1016/S0008-8846(97)00109-9. 